\title{
P02.54. Tools from the SPICER project for doing clinic-based research on integrative medicine and CAM
}

\author{
M Aickin \\ From International Research Congress on Integrative Medicine and Health 2012 \\ Portland, Oregon, USA. 15-18 May 2012
}

\section{Purpose}

Non-intervention research using clinical records is difficult, both from the theoretical and practical standpoints. Progress on the former requires progress on the latter. Several techniques have been developed in the SPICER project to overcome the various practical problems encountered in research from electronic medical records (EMRs). This presentation will exhibit techniques that have been developed and appear to work well.

\section{Methods}

Non-intervention projects on integrative medicine and pain are underway, one at a large $\mathrm{HMO}$ and another in a mixed conventional/CAM clinic. Both of these projects have addressed problems of refining research objectives, performing data extraction, and designing analyses.

\section{Results}

In-depth understanding of the EMR system, the clinic, and how practitioners use the system are necessary to identify patient samples and available information. A successful strategy for obtaining research datasets from EMR has been based on a radical simplification of the interface between the IT professionals and the analysis professionals. The post-extraction data manipulation burden is somewhat high, but must be faced because conventional data management techniques are infeasible. The well-known ICD9 and CPT codes can be simplified in medically appropriate ways, but EMRs often introduce non-standard features into these systems. Medications present unique problems, but the ACT (anatomic, therapeutic, chemical) annotation system is very useful in analysis datasets. Therapeutically relevant analyses

University of Arizona, Tucson, USA

(0) 2012 Aickin; licensee BioMed Central Ltd. This is an Open Access article distributed under the terms of the Creative Commons Attribution License (http://creativecommons.org/licenses/by/2.0), which permits unrestricted use, distribution, and reproduction in any medium, provided the original work is properly cited. must account for treatment selection bias. A reading list of resources will be provided.

\section{Conclusion}

EMR-based research is potentially an extremely valuable complement to other methods of medical investigation. Developing this alternative source of therapeutic knowledge requires dissemination of a toolkit that solves the practical problems.

Published: 12 June 2012

doi:10.1186/1472-6882-12-S1-P110

Cite this article as: Aickin: P02.54. Tools from the SPICER project for doing clinic-based research on integrative medicine and CAM. BMC Complementary and Alternative Medicine 2012 12(Suppl 1):P110.

Submit your next manuscript to BioMed Central and take full advantage of:

- Convenient online submission

- Thorough peer review

- No space constraints or color figure charges

- Immediate publication on acceptance

- Inclusion in PubMed, CAS, Scopus and Google Scholar

- Research which is freely available for redistribution 